\title{
Optiminization of regeneration at the stages of soft tissue augmentation using a collagen matrix
}

\author{
(c) A.B. Adzhieva, I.A. Voronov, S.S. Ivanov, H.M. Nalchajyan \\ "Peoples' Friendship University of Russia" (RUDN University), Moscow, Russia.
}

\begin{abstract}
:
Lack of adequate width and thickness of periodontal or peri-implant soft tissues can compromise the aesthetics, function or survival of teeth and dental implants.

Biomaterials are widely used in dentistry to overcome the disadvantages of autogenous tissue transplantation. The advantage of using biomaterials is that there is no need for re-surgery and that they are available in large quantities. The most widely used biomaterial for soft tissue augmentation is collagen, as it is believed to best mimic the natural cellular environment of the extracellular matrix, although other biomaterials are also candidates for soft tissue regeneration. Collagen matrices differ in composition, three-dimensional structure, elasticity and mechanical stability.

Aim. is to review the literature on the optimization of regeneration at the stages of soft tissue augmentation using a collagen matrix.
\end{abstract}

Keywords: autograft, collagen matrix, implantation, gum recession, soft tissue augmentation.

Received: 03.09.2021; revised 26.11.2021; accepted: 30.11.2021.

Conflict of interests: The authors declare no conflict of interests.

For citation: A.B. Adzhieva, I.A. Voronov, S.S. Ivanov, H.M. Nalchajyan. Optiminization of regeneration at the stages of soft tissue augmentation using a collagen matrix. Endodontics today. 2021; 19(4):317-319. DOI: 10.36377/1683-29812021-19-4-317-319.

\section{INTRODUCTION}

The absence of keratinized gingiva around dental implants increases the susceptibility of peri-implant tissues to bacterial biofilm-induced alteration [1]. In a study conducted by Bouri Jr A co - authorship (2008) demonstrated that increased keratinized gingiva width (2 $\mathrm{mm}$ ) around the implant was associated with reduced mean alveolar bone loss and improved soft tissue outcomes. Wide areas of keratinized gingiva can lead to increased resistance to chewing forces [2].

The presence of healthy attached gingiva at the soft tissue interface of the tooth and implant correlates with long-term success, aesthetics, and stability [8]. Not only does a lack of keratinized gingiva contribute to plaque accumulation around teeth and implants, but it can also lead to soft tissue recession in the aesthetic zone. An implant with adequate bone and soft tissue thickness is less prone to recession.

The consequences of lack of adequate keratinized gingiva around teeth have been widely studied for decades $[3,4,5,6]$. The presence of keratinized gingiva is closely related to optimal soft and hard tissue health. However, this is true for patients who maintain proper plaque formation control.

Even minimal amounts of keratinized gingiva can provide long-term soft tissue stability in the presence of good plaque control. Early studies showed that soft tissue recession around the implant might be the result of soft tissue remodeling around the dental implant. Lack of keratinized gingiva and peri-implant area soft tissue mobility were associated with more pronounced soft tissue recession around the implant.

Adequate width of keratinized attached mucosa around the dental implant could improve soft and hard tissue stability. Lack of keratinized gingiva was associated with plaque formation, greater soft tissue recession, and more areas that required additional surgical intervention. The above indicates that implants not surrounded by keratinized gingiva are more prone to plaque accumulation and soft tissue recession, despite adequate oral hygiene and supportive periodontal therapy [7].

The aim of this study is to increase the effectiveness of implant treatment at the stage of soft tissue augmentation with a collagen matrix, reducing the surgery time, minimizing postoperative complications, simplifying the doctor's work and reducing patient discomfort in the postoperative period.

The result of wound regeneration largely depends on the characteristics of the biomaterial (e.g., chemical structure, architecture, surface topography of the biomaterial). Ideally, the biomaterial should elicit a short and moderate inflammatory response, followed by a regeneration phase, but without a chronic reaction to the foreign body leading to encapsulation or even rejection of the biomaterial. Macrophages are among the first cells to come into contact with the implanted biomaterial. Biomaterial properties can modulate the phenotype of macrophages as shown by surface characteristics [9], and, as a consequence, the transition from inflammation (macrophages M1) to tissue repair and regeneration (macrophages $M 2$ ) can be impaired or delayed. Moreover, the biomaterial may induce the formation of multinucleated giant cells, which contribute to biomaterial degradation, or may indicate a reaction to a foreign body. Tissue integration is directly related to the inflammatory response and cell invasion of the biomaterial. A short inflammatory phase ensures an early start of the proliferative phase with penetration of mesenchymal cells into the biomaterial. Cell proliferation into the biomaterial is crucial for the integration of the biomaterial into the host tissue, which means high biocompatibility. In addition, 
the rigidity of the biomaterial determines the cell invasion and the type of cells into which the mesenchymal cells will differentiate. Cell invasion into collagen frameworks depends on the presence of highly interconnected pores. Moreover, cell proliferation at an early stage depends on the presence of vascular structures. Endothelial and fibroblastic cells work together, eventually leading to the filling of the voids in the biomaterial with collagen as part of the extracellular matrix.

The use of free connective tissue graft is a predictable and versatile method that creates a bilaminar vascular environment to nourish the graft $[10,11]$. However, healing of the donor site in the palatine area is painful and slow, which can lead to its complications. Also, we would like to note the limited volume of the necessary graft intake. There are also anatomical and individual limitations. Depending on the shape of the palatine vault [12], the patient's gender and age, the amount and quality of tissue that can be obtained. The location of the palatine vessels and nerves further limit the grafting procedure. To overcome these obstacles, alternative methods of soft tissue augmentation with a collagen matrix have been developed.

I would like to describe this alternative in more detail. This is a new highly porous and volume-stable collagen-based matrix (VSMC, Fibro-Gide ${ }^{\circledR}$ prototype, Geistlich Pharma AG, Wolhusen, Switzerland) for soft tissue augmentation around teeth and dental implants [13]. It has the properties of biocompatibility, blood vessels and progenitor cells sprout into it, as well as to withstand mechanical stresses in the early stages of postoperative engraftment resulting from suturing, wound compression and chewing, thereby maintaining the volume of newly formed tissue. In vivo and in vitro studies have demonstrated optimal mechanical, biological and anatomical properties of VSMCs [14, 15]. The collagen matrix consisted of $60-96 \%$ (wt/mass) Pig Collagen types I and III and 4-40\% (wt/mass) Elastin, had an average pore diameter of $92 \mu \mathrm{m}$ and a volume porosity of $93 \%$ with interconnected pores. The stiffness of the framework was achieved by chemical cross-linking. The framework remained elastic even after the application of mechanical forces for 14 days, which was evaluated in a dynamic bioreactor test system simulating mechanical loads in the human mouth in vivo [16]. Clinically, soft tissue augmentation using VSMCs resulted in an increase in volume not inferior to autogenous connective tissue grafts at dental implant sites in the aesthetically significant area [17] and minimal loss of soft tissue thickness 6 months after implantation [18]. However, the underlying biological process leading to these positive clinical outcomes is largely unknown.

The first insight into the tissue response and behavior of VSMCs after implantation was obtained in a recently published, empirical study [15]. However, there are currently no data on the characteristics of the cells invading VSMCs and the dynamic changes with the lapse of time. In Caballé-Serrano J co - authorship (2019) investigated the integration of macrophages, blood vessels, and proliferating cells into VSMCs used for soft tissue augmentation around teeth and dental implants. Biomaterial was implanted into the submucosal pockets of the dog's upper jaw, and the tissue response was analyzed at 6 different time points. Immunohistochemistry was performed for proliferating cells (PCNA), macrophages
(MAC387), multinucleated giant cells (CD86), and blood vessels (TGM2). Blood quickly filled the pores of VSMCs. During the first week, MAC387 cells populated the VSMC pores, blood vessels and PCNA cells integrated into VSMCs, and scattered CD86 cells were observed. After 15 days, MAC387 cells were scarce, blood vessels had fully invaded VSMCs, the number of proliferating cells peaked, and fibroblasts appeared. After 30 days, MAC387 was absent, the number of proliferating and CD86 cells had decreased, while the number of blood vessels and fibroblasts was high. After 90 days, residual VSMCs were well integrated into the connective tissue. As a result, the author showed that VSMC induced a short inflammatory phase followed by rapid integration into the tissue [19].

One of the main problems of biomatrixes for directed tissue regeneration is the instability of their volume and rapid degradation. In a study by Vallecillo C co - authorship (2021) studied the degradation of three matrixes over time [20]. To this end, $10 \times 10 \mathrm{~mm} 2$ Fibro-Gide, Mucograft, and Mucoderm pieces were subjected to three different decomposition tests: (1) hydrolytic decomposition in phosphate buffer solution (PBS); (2) enzyme resistance using $0.25 \%$ porcine trypsin solution; and (3) resistance to bacterial collagenase (Clostridium histolyticum), with different immersion periods up to 50 days. Weight measurements were made using analytical microbalances. Thickness was measured with a digital caliper. A stereomicroscope was used to obtain images of the matrices. ANOVA and Student-Newman-Keuls tests were used for comparisons of mean values ( $p<0.05)$, except for analysis of differences between time points within the same matrix and solution, where pairwise comparisons ( $\mathrm{p}<0.001$ ) were applied. Fibro-Gide achieved the highest resistance to all degradation problems. The bacterial collagenase solution was shown to be the most aggressive test as all matrices exhibited $100 \%$ degradation until 14 days of storage.

\section{CONCLUSIONS}

Although the use of autografts for soft tissue augmentation is still the gold standard nowadays, obtaining an autograft is not always possible due to factors such as lack of autograft tissue (a graft may have been taken earlier), additional operating field in the mouth, possible risks of complications such as bleeding, tissue necrosis in the area of the graft, therefore an alternative to autograft - soft tissue augmentation with a collagen matrix was considered.

In addition to the fact that the collagen matrix meets the above requirements, it should also be noted that when soft tissue augmentation is performed using the collagen matrix, the period of rehabilitation after surgery is much easier for the patients. In the postoperative period, pain syndrome is less pronounced, collateral edema is much less.

The collagen matrix greatly simplifies the operation. We must certainly note the convenience of its use in practice, the doctor himself cut out the necessary shape, according to pre-established marks for length, width and thickness. And this collagen matrix already has decent long-term clinical results.

To sum up, I would like to note that this technique of soft tissue augmentation has many advantages, which cannot but make both doctors and patients happy. 


\section{REFERENCES:}

1. Frizzera F, Oliveira GJPL, Shibli JA, Moraes KC, Marcantonio EB, Marcantonio Junior E. Treatment of peri-implant soft tissue defects: narrative review. Braz Oral Res. 2019; 33 (suppl 1):e073. Published 2019 Sep 30. doi:10.1590/1807-3107bor-2019.vol33.0073.

2. Bouri Jr A, Bissada N, Al-Zahrani MS, Faddoul F, Nouneh I. Width of keratinized gingiva and the health status of the supporting tissues around dental implants. Int J Oral Maxillofac Implants 2008; 23:323-6.

3. Zweers, Jeroen \& Thomas, R. \& Slot, Dagmar \& Weisgold, Arnold \& Weijden, G. (2014). Characteristics of periodontal biotype, its dimensions, associations and prevalence: A systematic review. Journal of clinical periodontology.

4. Chiu YW, Lee SY, Lin YC, Lai YL. Significance of the width of keratinized mucosa on peri-implant health. J Chin Med Assoc. 2015;78(7):389-394.

5. Moraschini V, Luz D, Velloso G, Barboza EDP. Quality assessment of systematic reviews of the significance of keratinized mucosa on implant health. Int J Oral Maxillofac Surg. 2017;46(6):774-781.

6. Deeb JG, Bencharit S, Loschiavo CA, Yeung M, Laskin D, Deeb GR. Do Implant Surgical Guides Allow an Adequate Zone of Keratinized Tissue for Flapless Surgery?. J Oral Maxillofac Surg. 2018;76(12):25402550.

7. Roccuzzo M, Grasso G, Dalmasso P. Keratinized mucosa around implants in partially edentulous posterior mandible: 10-year results of a prospective comparative study. Clin Oral Implant Res. 2016;27(4):491496.

8. S.I. Bulanov, A.D. Lysov, M.V. Sofronov. Rationale for the use of connective tissue autograft in dental implantation. Bulletin of Medical Institute "Reaviz": Rehabilitation, Doctor and Health. 2017 5(29): 81-94.

9. S.M. Kutepov, E.A. Volokitina, M.V. Gilev, Yu.V. Antoniadi, E.V. Pomogaeva. Augmentation of bone defects of the distal tibia with synthetic b-tricalcium phosphate and xenoplastic material "Osteomatrix" in surgical treatment of intraarticular impingement fractures. Genius Orthopedics. 2016. № 3:14-20.

10. M.D. Perova, N.V. Lapina, E.A. Fomicheva, V.B. Karpyuk, A.V. Tropina, A.A. Vziatyshev. Evaluation of autotransplantation of connective tissue palatal flap in combination with vascular-stromal-cell fraction of lipoaspirate in tissue recession (10 years of observations). Russian Journal of Stomatology; 2016. 20 (5):260-266.

11. Types of gingival grafts and their use in periodontal dentistry. E.V. Antipova, O.Yu. Ponomarev. Periodontology. 2016; T. 21; 2(79): 24-28.

\section{AUTHOR INFORMATION:}

A.B. Adzhieva - Postgraduate student, ORCID ID: 0000-0002-9196-6868.

I.A. Voronov - Doctor of Medical Sciences, Professor of the Department of Prosthodontic Dentistry

S.S. Ivanov - Postgraduate student, ORCID ID: 0000-0002-4058-1706.

H.M. Nalchajyan - Postgraduate student, ORCID ID: 0000-0002-6741-4916.

"Peoples' Friendship University of Russia" (RUDN University), Moscow, Russia.
12. L.F. Razheva, V.A. Kravchenko, V.G. Shchulzhenko, N.N. Yakimov. Transplantation operation of full-layer mucosal graft from the area of hard palate. Healthcare of the Far East. 2013; 2(56):107-111.

13. Thoma, D.S.; Zeltner, M.; Hilbe, M.; Hammerle, C.H.; Husler, J.; Jung, R.E. Randomized controlled clinical study evaluating effectiveness and safety of a volume-stable collagen matrix compared to autogenous connective tissue grafts for soft tissue augmentation at mplant sites. J. Clin. Periodontol. 2016; 43, 874-885

14. Thoma, D.S.; Nanni, N.; Benic, G.I.; Weber, F.E.; Hammerle, C.H. Jung, R.E. Effect of platelet-derived growth factor-BB on tissue integration of cross-linked and non-cross-linked collagen matrices in a tectopic model. Clin. Oral Implants Res. 2015, 26, 263-270.

15. Ferrantino, L.; Bosshardt, D.; Nevins, M.; Santoro, G.; Simion,M.; D. Tissue Integration of a Volume-Stable Collagen Matrix in an . Int. J. Periodont. tor. Dent. 2016, 36, 807-815.

6. Mathes, S.H.; Wohlwend, L.; Uebersax, L.; von Mentlen, R. Ther D.S.; Jung, R.E.; Gorlach, C.; Graf-Hausner, U. A bioreactor to evaluate substitutes for connective tissue grafts. . Bioeng. 2010, 107, 1029-1039.

(t)er, M.; Jung, R.E.; Hammerle, C.H.; Husler, J.; Thoma, ( collagen matrix to autogenous connective tissue grafts for soft tissue augmentation at implant sites: Linear volumetric soft tissue changes up 3 months. J. Clin. Periodontol. 2017, 44, 446-453.

18. Thoma, D.S.; Naenni, N.; Benic, G.I.; Hammerle, C.H.; Jung, R.E. Soft tissue volume augmentation at dental implant sites using a volume stable three-dimensional collagen matrix-Histological outcomes of a preclinical study. J. Clin. Periodontol. 2017, 44, 185-194.

19. Caballé-Serrano J, Zhang S, Ferrantino L, Simion M, Chappuis $V$, Bosshardt DD. Tissue Response to a Porous Collagen Matrix Used for Soft Tissue Augmentation. Materials (Basel). 2019;12(22):3721. Published 2019 Nov 11. doi:10.3390/ma12223721.

20. Vallecillo C, Toledano-Osorio M, Vallecillo-Rivas M, Toledano M, sorio R. In Vitro Biodegradation Pattern of Collagen Matrices for Soft Tissue Augmentation. Polymers (Basel). 2021;13(16):2633. Published 2021 Aug 7. doi:10.3390/polym1316263

Координаты для связи с авторами / Coordinates for communication with authors: Аджиева А.Б./ А.В. Adzhieva, E-mail: Aanzhoka@mail.ru 